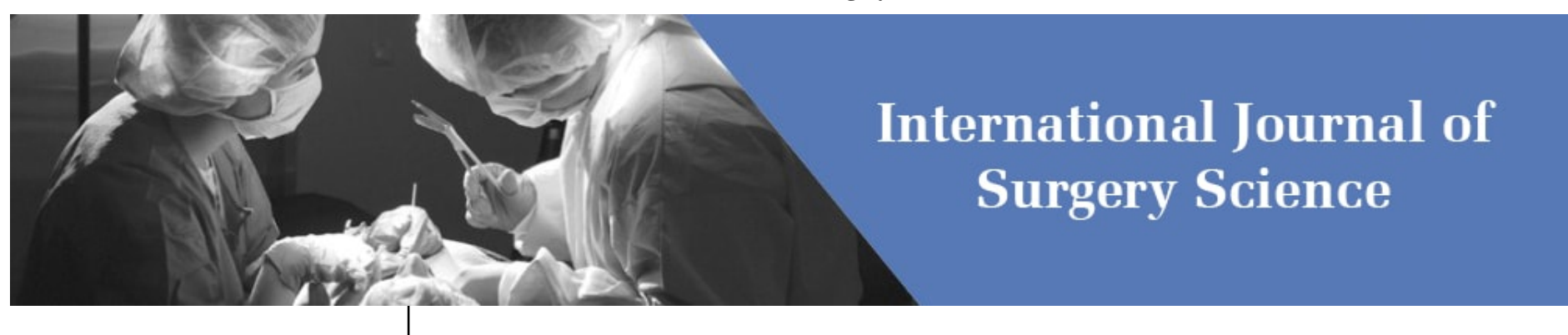

E-ISSN: 2616-3470

P-ISSN: 2616-3462

(C) Surgery Science

www.surgeryscience.com

2021; 5(3): 106-110

Received: 05-06-2021

Accepted: 25-06-2021

\section{Dr. M Manohar}

Assistant Professor, Department of General Surgery, Kakatiya Medical College/MGM Hospital, Warangal, Telangana, India
Corresponding Author:

Dr. M Manohar

Assistant Professor, Department of General Surgery, Kakatiya Medical College/MGM Hospital, Warangal,

Telangana, India

\title{
A clinico-pathological study of acute appendicitis with management and the role of ultrasound in diagnosis of appendicitis
}

\section{Dr. M Manohar}

DOI: https://doi.org/10.33545/surgery.2021.v5.i3b.749

\section{Abstract}

Background: Acute appendicitis is the most common cause of acute surgical abdomen and appendicectomy is the most commonly done emergency surgery. Its diagnosis remains an enigmatic challenge, plagued by a high rate of negative explorations. There is no single reliable test with satisfactory, sensitivity and specificity.

Aim and Objective: The objective of the study is to evaluate the clinical presentations, signs of acute appendicitis and its management. The role of USG in diagnosing acute appendicitis and reducing the rate of negative appendicectomies.

Methodology: The present study was conducted in 100 patients who have been clinically diagnosed of having Acute Appendicitis and posted for emergency appendicectomy in General Surgery, Department of MGM, attached to Kakatiya Medical College, Warangal, during the period from January 2018 to June 2020. Preoperatively blood for WBC count, DC and USG abdomen were done. All patients were subjected to histopathological examination postoperatively which was taken as gold standard. Results of Ultrasound were correlated with HPE reports to evaluate their role in diagnosis of acute appendicitis.

Results and Observations: In the present study we had 100 cases of which 61 (61\%) were males and 39 (39\%) were females. The number of patients was highest in the age group 20 to 29years (33\%). Migrating Pain to RIF was found in $76 \%$ of patients, Anorexia in $87 \%$ of patients. Nausea/vomiting were present in $79 \%$ patients. Right iliac fossa tenderness was found in $98 \%$ of cases. Rebound tenderness was found in $68 \%$ of patients. Fever was present in $45 \%$ of cases. Total leucocyte count was elevated in $80 \%$ of cases in our present study. Shift to let was seen in $42 \%$ cases. In our study all the patients were subjected to abdominal ultrasound examination. The sensitivity and specificity of Ultrasonography for acute appendicitis is $94.8 \%$ and $80 \%$ respectively. Accuracy was $93 \%$. The positive predictive value and negative predictive value of Ultrasonography for acute appendicitis is $98 \%$ and $44 \%$ respectively. Negative appendectomy rate in this study 5.5\%.The majority (60\%) is seen in females.

Conclusion: Ultrasound is a fast, simple, reliable, non-invasive, repeatable and safe diagnostic modality without any complications. It has greater sensitivity and positive predictive value in diagnosing acute appendicitis and it reduces the rate of negative appendicectomy.

Keywords: Ultrasonography, appendicectomy, WBC, diagnosis, fossa tenderness

\section{Introduction}

Acute Appendicitis is the most common general surgical emergency. It presents with protean manifestations, generous overlap with other clinical syndromes, and significant morbidity, which increases with diagnostic delay.

No single sign, symptom, or diagnostic test accurately confirms the diagnosis of appendiceal inflammation in all cases, and the classic history of anorexia and periumbilical pain followed by nausea, right lower quadrant (RLQ) pain, and vomiting occurs in only $50 \%$ of cases.

Simple appendicitis can progress to perforation, which is associated with a much higher morbidity and mortality, and surgeons have therefore been inclined to operate when the diagnosis is probable rather than wait until it is certain. However, the differential diagnosis of appendicitis is often a clinical challenge because appendicitis can mimic several abdominal conditions.

Abdominal ultrasonography is a popular imaging modality for acute appendicitis. It is widely available, non-invasive and avoids ionizing radiation.

Despite diagnostic and therapeutic advancement in medicine, appendicitis remains a clinical 
emergency and is one of the most common causes of acute abdominal pain.

My study has included the current approach in diagnosis and management of acute appendicitis \& its complications by using Ultrasound Abdomen, Alvarado score, along with other investigations \& Histopathology.

\section{Aim and Objectives}

- To study the different modalities of presentation of acute appendicitis, the diagnosis and management.

- To study the role of ultrasound and to evaluate the sensitivity and specificity of sonography in the diagnosis of acute appendicitis

\section{Methodology}

Patients who present with symptoms \& signs of acute appendicitis and willing for admission MGM Hospital, Warangal under various surgical units, During the period of January 2018 to June 2020.

\section{Inclusion criteria for the study}

1. Patients willing for investigation and surgery

2. Patients aged 15 years and above and of either sex.

\section{Exclusion criteria for the study \\ 1. Pregnant females. \\ 2. Patients age -14 years and below \\ 3. Patient with recent history of any abdominal surgeries}

\section{Sample size: 100}

After initial assessment of patients presenting to the Out Patient department or emergency department of MGM Hospital, Warangal with symptoms and signs suggestive of acute appendicitis, who met the inclusion criteria admitted and are initially subjected for Detailed history taking, Clinical examination Investigations like Haematological investigations, urine routine, X-ray. Abdomen / chest, USG abdomen as required.

Following which they were evaluated using the Alvarado scoring.

The ultrasonographic examination was performed, initially with a hand held 3.5 MHz sector probe, in which the entire abdomen was scanned to exclude possible differential diagnosis of acute appendicitis. A $5 \mathrm{MHz}$ sector probe scan of the right lower quadrant, using the graded compression technique as described by Puylaert followed. The patient was asked to identify the site of maximum tenderness (self-localization) and graded compression was used to displace bowel loops in that area. The presence of a tubular, non- compressible, non-peristaltic, blind ending structure in the right iliac fossa, with a diameter of more than $6 \mathrm{~mm}$ was taken as significant. Other signs were recorded with special reference to peri-appendiceal collection and appendicolith.

Treatment was planned, depending upon the type of appendicitis and the presence or absence of complications. Pre-operative preparation consisted of bed rest, parental fluids, electrolytes, antibiotics and nasogastric aspiration. The decision to operate was taken solely by the treating surgeon, on the basis of clinical impression and ultrasonographic findings.

Acute cases were treated with emergency surgery. Appendicular mass cases were chosen for elective surgery. Anesthesia was either general or spinal anesthesia.

Abdomen was opened by Mc. Burney’s. In a few cases, incision had to be extended laterally and upwards. Appendectomy was done and in the majority of cases, stump ligated with linen thread and no invagination was done. In a few cases, the stump was invaginated. Drains were kept when found necessary. Abdomen was closed in layers, using Vicryl for peritoneum, muscles and fascia, and interrupted silk or nylon sutures for skin. The final diagnosis of acute appendicitis was confirmed by histopathology report. After surgery the patients were discharged on 3-7days except in cases of complications.

\section{Results}

Table 1: Age incidence

\begin{tabular}{|c|c|c|c|c|c|c|}
\hline Age(years) & \multicolumn{2}{|c|}{ Male } & \multicolumn{2}{c|}{ Female } & \multicolumn{2}{c|}{ Total } \\
\hline & No & \% & No & \% & No & \% \\
\hline $15-19$ & 17 & 27.9 & 11 & 28.2 & 28 & 28 \\
\hline $20-29$ & 19 & 31.1 & 14 & 35.9 & 33 & 33 \\
\hline $30-39$ & 17 & 27.9 & 7 & 17.9 & 24 & 24 \\
\hline $40-49$ & 4 & 6.6 & 4 & 10.3 & 8 & 8 \\
\hline $50-59$ & 2 & 3.3 & 3 & 7.7 & 5 & 5 \\
\hline$>60$ & 2 & 3.3 & 0 & 0 & 2 & 2 \\
\hline Total & 61 & & 39 & & 100 & \\
\hline
\end{tabular}

\section{Gender and Age distribution in acute appendicitis}

In the present study, out of 100 cases, only 39 cases occurred in females, and the remaining 61 cases occurred in males. The male to female ratio in the present study is approx. 1.56:1.

In males most common age group of presentation of acute appendicitis was between (20-29) (31.1\%) followed by the age group (15-219 years) (17.9\%) and age group (30-39) (17.9\%).

In females also the most common age group of presentation was between age group of 20-29 years (35.9\%) followed by age group of $15-19$ years (28.2\%).

Table 2: Sex incidence

\begin{tabular}{|c|c|c|}
\hline Sex & Number & \% \\
\hline Male & 61 & 61 \\
\hline Female & 39 & 39 \\
\hline Total & 100 & 100 \\
\hline
\end{tabular}

In our study, out of 100 cases 61 were males and 39 were females. This is statistically insignificant with p value of 0.028 .

Table 3: Symptoms of acute appendicitis

\begin{tabular}{|c|c|c|c|}
\hline Symptoms & Present & Absent & Total \\
\hline Migrating RIF Pain & 76 & 24 & 100 \\
\hline Anorexia & 87 & 13 & 100 \\
\hline Nausea/vomiting & 79 & 21 & 100 \\
\hline
\end{tabular}

In this study Migrating Right iliac fossa pain was present in $76 \%$ of patients which is significant. Anorexia was present in $87 \%$. Nausea/vomiting were present in $79 \%$ of patients. All the above are statistically significant.

Table 4: Signs in acute appendicitis

\begin{tabular}{|c|c|c|c|}
\hline Signs & Present & Absent & Total \\
\hline Fever & 45 & 55 & 100 \\
\hline Rif tenderness & 98 & 2 & 100 \\
\hline Rebound tenderness & 68 & 32 & 100 \\
\hline
\end{tabular}

In the present study Fever ( $>38 \mathrm{C}$ ) was present only in $45 \%$ of the patients and was absent in $55 \%$ of patients. Rif tenderness was present in statistically significant $98 \%$ of the patients. Rebound tenderness was present in $68 \%$ of patients. 
Table 4: Leucocyte count \& shift to let in acute appendicitis

\begin{tabular}{|c|c|c|c|}
\hline Leucocyte & Present & Absent & Total \\
\hline Total count raised (>12,000) & 80 & 20 & 100 \\
\hline Shift to left (d.c) (75\% neutrophils) & 42 & 58 & 100 \\
\hline
\end{tabular}

In our study total count was raised in $80 \%$ of patients with $\mathrm{P}$ value of 0.000 which is statistically significant. Shift to left was present in $42 \%$ of patients and was statistically insignificant.

Table 5: Duration of hospital stay

\begin{tabular}{|c|c|}
\hline Duration ( in days ) & Total number of patients \\
\hline$\leq 2$ & 23 \\
\hline $3-5$ & 56 \\
\hline $6-7$ & 18 \\
\hline$>7$ & 3 \\
\hline
\end{tabular}

In our study, majority of the patients stayed in the hospital for a duration of 3-5 days (56) followed by those who stayed for less than 2 days (23). Surgical site infection was the major cause for late discharge.

Table 6: Ultrasound findings

\begin{tabular}{|c|c|}
\hline USG findings & Number \\
\hline Appendicitis & 76 \\
\hline Appendicular Abscess & 3 \\
\hline Appendicular Mass & 6 \\
\hline Appendicular Perforation & 6 \\
\hline Normal study & 11 \\
\hline & $\mathbf{1 0 0}$ \\
\hline
\end{tabular}

In our study all the patients were subjected to abdominal ultrasound examination.76 patients had features suggestive of Acute Appendicitis, 6 patients had appendicular mass and 6 patients had appendicular perforation.11 patients had Normal study on Ultrasonography out of which 9 were clinically (Alvarado scoring more 5 or more) found to have appendicitis and underwent appendectomy. Remaining 2 patients were managed conservatively Out of this 6 cases which had Appendicular Mass and 3 patients who had Alvardo score of less than 4 were managed conservatively. Remaining 91 patients underwent open Appendectomy.

Table 7: USG and HPE correlation

\begin{tabular}{|c|c|c|c|}
\hline USG & HPE positive & HPE negative & Total \\
\hline Positive & 81 (true positive) & ( false positive) & 82 \\
\hline Negative & 5 (false negative) & 4 (true negative) & 9 \\
\hline Total & 86 & 5 & 91 \\
\hline
\end{tabular}

Table 8: USG statistical measure of performance

\begin{tabular}{|c|c|}
\hline Sensitivity & $94.8 \%$ \\
\hline Specificity & $80 \%$ \\
\hline Predictive value of positive test & $98 \%$ \\
\hline Predictive value of negative test & $44 \%$ \\
\hline Accuracy & $93 \%$ \\
\hline
\end{tabular}

Table 9: Intra operative findings

\begin{tabular}{|c|c|c|}
\hline Intra operative Findings & Number of Patients & $\mathbf{\%}$ \\
\hline Normal & 9 & 9.8 \\
\hline Inflammed appendix & 65 & 71.4 \\
\hline Perforated appendix & 9 & 9.8 \\
\hline Gangrenous appendix & 8 & 8.7 \\
\hline Total & 91 & 100 \\
\hline
\end{tabular}

\section{Distribution of cases as per Alvarado's score}

In our study all the cases were subjected to Alvarado scoring system, to clinically evaluate the patients. Those with scores of 5 or more were operated upon and score below 4 was managed conservatively.

Table 10: Alvarado score in study group

\begin{tabular}{|c|c|}
\hline Alvarado's score & Number of patients \\
\hline$<3$ & 0 \\
\hline 4 & 3 \\
\hline 5 & 9 \\
\hline 6 & 11 \\
\hline 7 & 24 \\
\hline 8 & 19 \\
\hline 9 & 28 \\
\hline 10 & 6 \\
\hline TOTAL & 100 \\
\hline
\end{tabular}

In our study scores suggestive of acute appendicitis (5 or more) was found to be present in 97 patient and 3 patients had scores of less than 4 and were managed conservatively. Of the 91 cases that were operated upon 5 had Normal Histopathological report.

Table 11: Correlation of clinical findings (Alvarado score) with HPE findings

\begin{tabular}{|c|c|c|c|}
\hline \multirow{2}{*}{ Alvarado score } & \multicolumn{2}{|c|}{ Histopathology } & \multirow{2}{*}{ Total } \\
\cline { 2 - 3 } & Positive & Negative & \\
\hline$<5$ & 0 & 0 & 0 \\
\hline $5-6$ & 17 & 5 & 22 \\
\hline$\geq 7$ & 69 & 0 & 69 \\
\hline Total & 86 & 5 & 91 \\
\hline
\end{tabular}

In our study majority of patients (69) had Alvarado score of more than 7 which was statistically significant with p value of 0.000 .The second most common group was that of scores between 5 to 6 (22).

Table 12: USG Findings and negative appendicectomy

\begin{tabular}{|c|c|c|c|c|}
\hline \multirow{2}{*}{$\begin{array}{c}\text { USG finding with } \\
\text { appendicular pathology } \\
\text { who underwent Surgery }\end{array}$} & $\begin{array}{c}\mid 4 \\
\text { Histopathology findings }\end{array}$ \\
\cline { 2 - 5 } & $\begin{array}{c}\text { Positive for } \\
\text { appendicular } \\
\text { pathology }\end{array}$ & $\%$ & $\begin{array}{c}\text { Negative } \\
\text { (normal) }\end{array}$ & $\%$ \\
\hline 91 & 86 & 94.5 & 5 & 5.4 \\
\hline
\end{tabular}

Our study, 86 patients out of 91 who were diagnosed and operated as Appendicitis had Positive histopathological confirmation of the disease. Five patients were found to be Negative for histopathological Features of Appendicitis.

\section{Discussion}

The discussion is based on the observations and analysis of the results in the study of 100 cases with regard to incidence, age, sex, symptoms, signs, Alvarado scoring system investigation operative findings, and histopathological examination.

\section{Clinical features Age incidence}

Table 13: Age incidence compared with various Authors In the present study the common age group found was 20-29 year (33\%)

\begin{tabular}{|c|c|c|}
\hline Author & Age group & Percentage \\
\hline Gallendo gallego et al. ${ }^{[5]}$ & $20-30 \mathrm{yr}$. & 52.00 \\
\hline Present study & $20-29 \mathrm{yr}$. & 33.0 \\
\hline
\end{tabular}




\section{Sex incidence}

It has been established beyond doubt by several authors that male Sex predominated over female in the incidence of acute appendicitis.

Table 14: Sex incidence compared with various Authors

\begin{tabular}{|c|c|}
\hline Author & M;F Ratio \\
\hline${\text { Hardwig korner } \text { et al. }{ }^{[6]}}^{[6]}$ & $1.4: 1.00$ \\
\hline David g addiss et al. ${ }^{[7]}$ & $1.4: 1.00$ \\
\hline Present study & $1.56: 1$ \\
\hline
\end{tabular}

\section{Pain}

Pain was a complaint in all the cases in this study. The classical migrating pain in which the initial location of pain in most cases presented with pain around umbilicus followed by in the right lower quadrant was seen in $76 \%$ of the patients. This has sensitivity, $81 \%$; specificity, 53\%.

\section{Anorexia}

Anorexia was present in $87 \%$ of patients in present series. Anorexia nearly always accompanies appendicitis.

Table 15: Anorexia compared with various Authors

\begin{tabular}{|c|c|}
\hline Author & Percentage \\
\hline George Mathews, et al. $^{[8]}$ & 92 \\
\hline Kallan M et al. ${ }^{[9]}$ & 85 \\
\hline Present study & 87 \\
\hline
\end{tabular}

\section{Nausea or Vomiting}

Nausea /Vomiting was present in $79 \%$ of cases in present series. In George Mathew et al., nausea was present in $92 \%$ and vomiting in $70.9 \%$.

\section{Right Iliac fossa tenderness}

Right iliac fossa tenderness was present in $98 \%$ the cases at the time of presentation, a major contribution for diagnosis of Acute Appendicitis.

Table 16: Right iliac Fossa tenderness compared with various Authors

\begin{tabular}{|c|c|}
\hline Author & Percentage \\
\hline Gallindo Gallego et al. ${ }^{[5]}$ & 94 \\
\hline George Mathews et al. ${ }^{[8]}$ & 99 \\
\hline Present study & 98 \\
\hline
\end{tabular}

\section{Rebound Tenderness}

In the present series, $68 \%$ of the cases had rebound tenderness.

Table 17: Rebound tenderness compared with various Authors

\begin{tabular}{|c|c|}
\hline Author & Percentage \\
\hline${\text { Gallindo Gallego } \text { et al. }^{[5]}}^{[5]}$ & 56 \\
\hline Owen Td et al. $^{[10]}$ & 60 \\
\hline Present study & 68 \\
\hline
\end{tabular}

\section{Fever}

Fever was present in 44 cases (44\%) in present series. In the majority of cases fever was of low grade and continues: the incidence of fever in the Literature and the present series is compared in the following tables.

Table 18: Fever compared with various Authors

\begin{tabular}{|c|c|}
\hline Author & Percentage \\
\hline Kallan M et al. ${ }^{[11]}$ & 40 \\
\hline Wilcox et al. ${ }^{[12]}$ & 50 \\
\hline Present study & 44 \\
\hline
\end{tabular}

USG Sensitivity and Specificity in diagnosis of acute appendicitis

In the present study USG findings showed $94.8 \%$ sensitivity and $80 \%$ specificity in diagnosing acute appendicitis. Compared with various authors in the following table.

Table 19: USG Sensitivity and Specificity compared with various Authors

\begin{tabular}{|c|c|c|}
\hline Author & Sensitivity & Specificity \\
\hline Puylaert JBCM et al. $^{[13]}$ & 89 & 100 \\
\hline${\text { Gallindo Gallego } \text { et al. }^{[5]}}^{\left[{ }^{[14]}\right.}$ & 89 & 82 \\
\hline Jeffrey et al. ${ }^{[1]}$ & 89.9 & 96.2 \\
\hline Ziedan et al. ${ }^{[5]}$ & 74.2 & 93.7 \\
\hline Present study & 94.8 & 80 \\
\hline
\end{tabular}

\section{Alvarado's Score}

In this series $77 \%$ of patients had Alvarado score of 7 or more than 7 .

Table 20: Alvarado score of 7 or more compared with various Authors

\begin{tabular}{|c|c|}
\hline Author & Percentage \\
\hline Bhattacharjee et al. ${ }^{[16]}$ & 82.25 \\
\hline Sudhir Kumar Mohanty et al. ${ }^{[17]}$ & 81.61 \\
\hline Present study & 77 \\
\hline
\end{tabular}

\section{Negative appendicectomy rate}

The present study shows negative appendicectomy rate of 5.5\%. Out of this $60 \%$ were seen in females. This is high negative appendicectomy. This is probably due to pelvic inflammatory diseases, and ruptured follicular cysts.

\section{Conclusion}

In the present study we had 100 cases of which 61 were males and 39 were females. In the study 91 were operated and acute appendicitis was found in 86 patients. So we conclude

- Ultrasound can therefore be used as a cheap and inexpensive way of confirming acute appendicitis thus reducing negative appendicectomy rate.

- Ultrasonography increases the diagnostic accuracy in patients with suspected acuter appendicitis to the tune of 93\%.

- Its application can reduce negative appendicectomy rate which is $5.5 \%$ in our study.

- Thus Ultrasound is very effective in the diagnosis of acute appendicitis in both men and females. It rules out Pelvic pathology in female which decreases the negative appendicectomy rate.

- In the diagnosis of acute appendicitis, the Ultrasound is a simple, reliable, non- invasive, repeatable and safe diagnostic modality without complications.

- Ultrasound is useful in the diagnosis of acute appendicitis and its complications with a sensitivity and specificity 94.8\% and $80 \%$ respectively.

- Thorough history taking, evaluation of the clinical symptoms and signs combined with the specific tests and Ultrasound abdomen can improve the diagnostic accuracy and significantly reduce the rate of negative appendectomy.

\section{Acknowledgment}

The author is thankful to Department of General Surgery for providing all the facilities to carry put this work. 


\section{Conflict of Interest}

None

\section{Funding Support}

Nil

\section{References}

1. William Peranteau H. Douglas Smink S. Maingot's Abdominal Operations $12^{\text {th }}$ edition: Michael J Zinner, Stanley W. Ashley 2013, 623.

2. Mike Liang K, Roland Andersson E, Bernard Jaffe M, David Berger H. The Appendix: Schwartz Principals of Surgery $10^{\text {th }}$ edition.

3. David A, McClusky III, John E. Skandalakis. Appendix: Skandalakis' Surgical Anatomy: The Embryologic and Anatomic Basis of Modern Surgery, $4^{\text {th }}$ edition 2004.

4. John Maa, Kimberly S. Kirkwood: The Appendix: Sabiston textbook of Surgery The Biological basis of modern surgical practise $19^{\text {th }}$ edition 2012.

5. GallindoGallego, Fadrique, Neto, Calleja, Fernandej; evaluation of ultrasonograpy and clinical diagnostic scoring in suspected appendicitis Br. J Surg 1998;85:3740.

6. Körner H, Söndenaa K, Söreide JA, Andersen E, Nysted A, Lende $\mathrm{TH}$ et al. Incidence of acute non-perforated and perforated appendicitis: age-specific and sex-specific analysis. World J Surg 1997;21(3):313-7.

7. Addlss DG. (CDC, Atlanta, GA 30333), Shaffer N, Fowler BS, Tauxe RV. The epidemiology of appendicitis and appendectomy in the United States. Am J Epidemiol 1990;132:910-25.

8. George Mathews John, Siba Prasad Pattanayak, Charan Panda, K. Raja Ram Mohan Rao, Evaluation of Ultrasonography as a Useful Diagnostic Aid in Appendicitis. IJS 2002;64(5):436-439.

9. Kallan M, Talbot D, Cunliffe WJ, Rich AJ. Evaluation of modified Alvarado Score in diagnosis of Acute Appendicitis: A prospective study. Ann, RCS of Engl 1994;76(6):418-419.

10. Owen TD, William H. Stiff G, Jenkenson LR, Rees B1. Evaluation of Alvarado Score in Acute Appendicitis: Journal of social medicine 1992;85:87-88.

11. Kallan M, Talbot D, Cunliffe WJ, Rich AJ. Evaluation of modified Alvarado Score in diagnosis of Acute Appendicitis: A prospective study. Ann, RCS of Engl 1994;76(6):418-419.

12. Wilcox RT, Traverso LW. Have the evaluation and Treatment of acute appendicitis changed with new technology? Surg clin North A 1997;77:1355-1317.

13. Puylaert, JBCM et al. Acute Appendicitis visualization using graded-compression radiology 1986;158:355-360.

14. Jeffrey RB, Jr, Laing FC, Townsend RR. Acute appendicitis: sonographic criteria based on 250 cases. Radiology 1988;167:327-329.

15. Zeidan BS, Wasser T, Nicholas GG Ultrasonography in the diagnosis of acute appendicitis. J R Coll Surg Edinb 1997;42(1):24-6.

16. Bhattacharjee PK, Chowdary T, Roy D. Prospective Evaluation of modified Alvarado Score for diagnosis of acute appendicitis: journal of Indian medical Association 2002, 100.

17. Sudhirkumar Mohanty, Kaushik Si. Evaluation of modified Alvarado score in decreasing negative appendicectomy rateour experience, IJS 2000;62(5):342-343. 